\title{
FRACTURE-DISLOCATIONS OF THE CERVICAL SPINE
}

\author{
F. C. Durbin, Exeter, England
}

From the Princess Elizabeth Orthopaedic Hospital and the Royal Devon and Exeter Hospital, Exeter

For centuries spinal injuries, and in particular those involving the cervical region, have been feared more than any others by the layman because they are so often associated with paralysis and death. A clinical description was recorded in the Edwin Smith papyrus (Power 1934) by a medical author who wrote in 2500 B.C.: " One having a crushed vertebra of his neck he is unconscious of his two arms and legs and he is speechless-an ailment not to be treated." This gloomy first reference is quoted many times in a vast literature on fracture-dislocation of the cervical spine, a condition that still presents many difficulties in its treatment. The early methods were primitive, the patient being tied upside down to a ladder which was violently shaken, the presumption being that any dislocation might be reduced by this means. Hippocrates later used a more rational form of treatment and applied traction to the neck of the recumbent patient, but these cases were seldom treated successfully until the beginning of this century.

Eastwood (1940) pointed out that the cervical spine may be divided clinically into two distinct areas, the first two vertebrae and the last five. Since the first two vertebrae have a different shape from the remainder, the movement taking place between them is different from that in the lower segments. Rotational movement is the primary function of the atlas and axis, three-quarters of the total rotation of the cervical spine taking place between them.

The purpose of this paper is to report seventy-five injuries of the cervical spine treated in the orthopaedic service at Exeter during the years 1946-1955. Sixty-three of the cases involved the lower cervical vertebrae, and the importance of early operative treatment is emphasised in all dislocations of this region.

Injuries of the atlas and axis have been extensively reviewed recently by Grogono (1954) and a description here would be superfluous.

\section{CLINICAL MATERIAL}

The site and nature of the injury in the seventy-five cases are summarised in Table I.

TABLE I

Clinical Material

\begin{tabular}{|cccccc|}
\hline $\begin{array}{c}\text { Injuries } \\
\text { of atlas } \\
\text { and axis }\end{array}$ & $\begin{array}{c}\text { Fractures C.3-7 } \\
\text { uncomplicated } \\
\text { by dislocation }\end{array}$ & $\begin{array}{c}\text { Fracture- } \\
\text { dislocations } \\
\text { C.3-7 }\end{array}$ & $\begin{array}{c}\text { Dislocations } \\
\text { C.3-7 }\end{array}$ & $\begin{array}{c}\text { Hyperextension } \\
\text { injuries } \\
\text { C.3-7 }\end{array}$ & Total \\
\cline { 6 - 7 } & 72 & 24 & 29 & 3 & 75 \\
\hline
\end{tabular}

Sex-Sixty patients were male and sixteen female.

Age-The youngest patient was fourteen and the oldest ninety (Fig. 1). Young active males were in a preponderance.

\section{CAUSE OF INJURY}

The commonest cause is a road accident, but in the present series sport injuries of various kinds were frequent (Table II). These included diving into shallow water, rugby football, gymnastics and riding. Falling downstairs or from a height is also a common cause. In a farming community an additional hazard is forcible flexion of the neck while milking a cow, her 


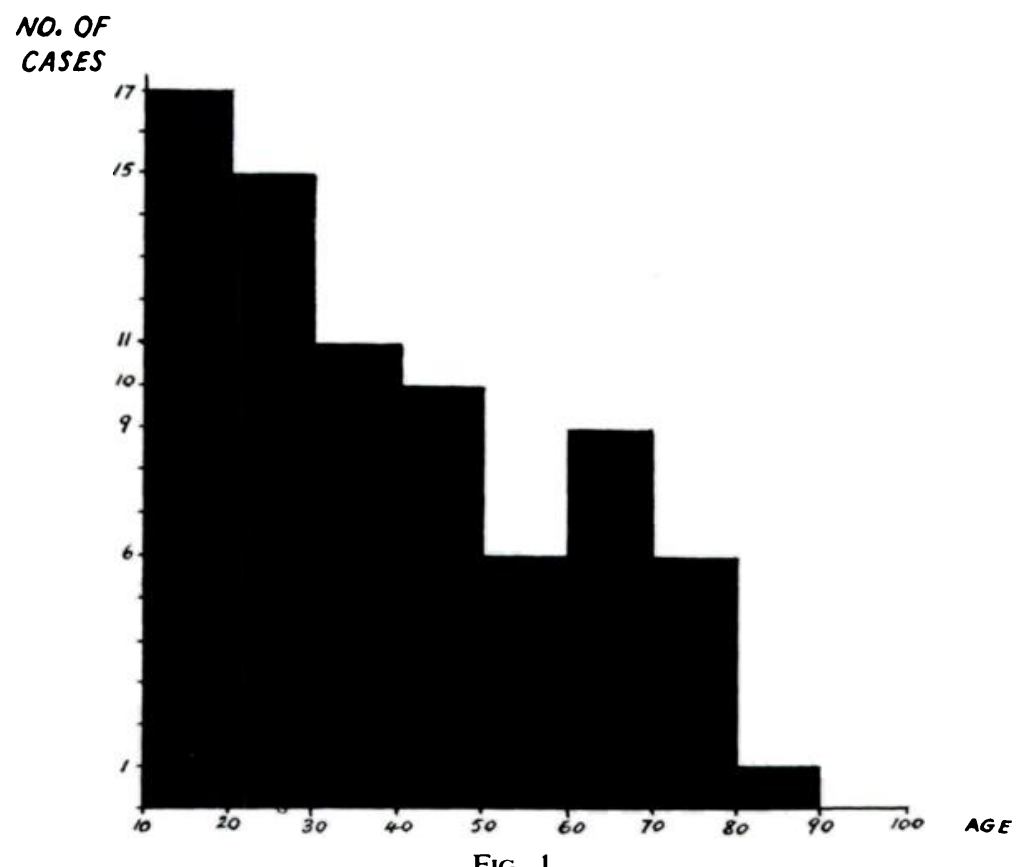

Age incidence in seventy-five cases of injury to the cervical spine.

TABLE II

analysis of Cause of accident and Incidence of Paraplegia in Seventy-five Cases

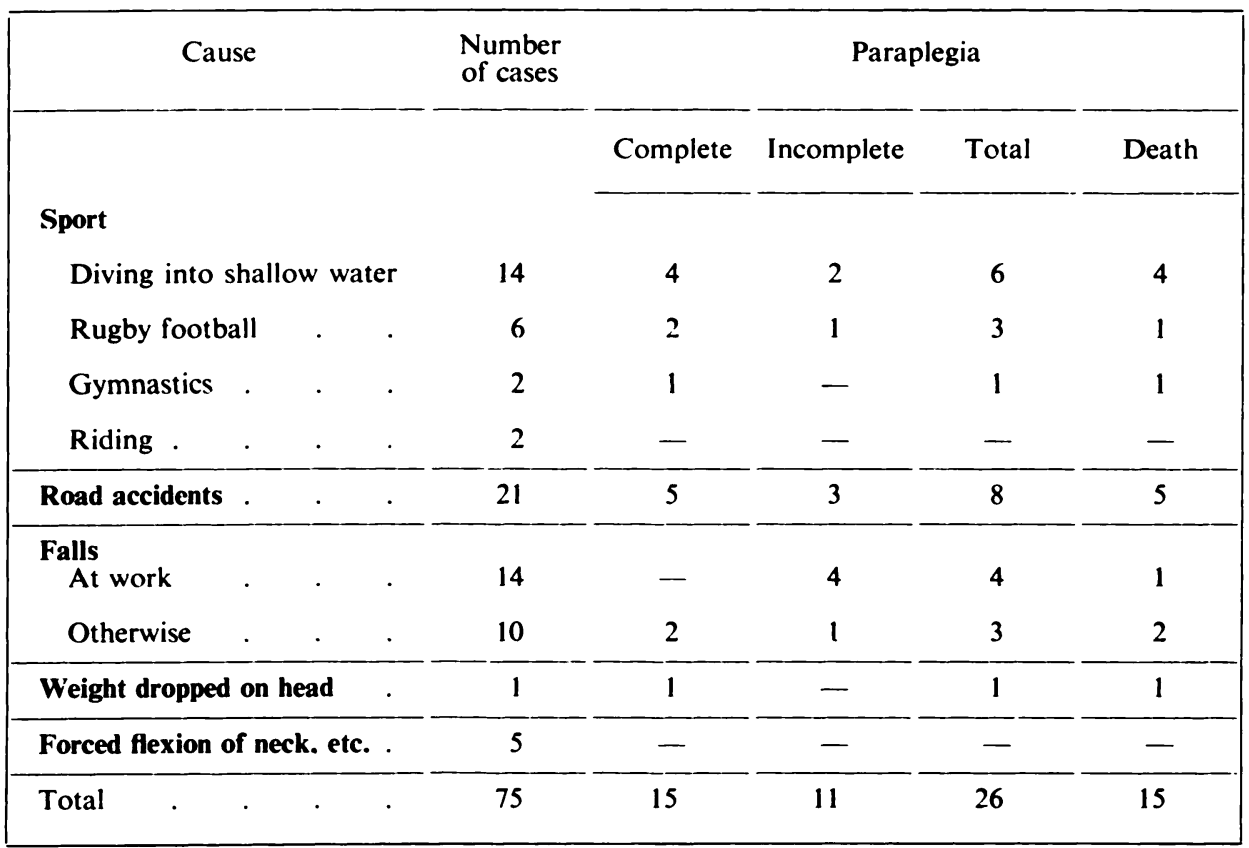


sudden movement compressing the milker against the side of the stall. Industrial accidents, except among miners, do not often affect the cervical spine. Riding accidents strangely enough were an infrequent cause even though Devon is a county where hunting is popular and hazardous.

\section{LEVEL OF LESION}

The vertebrae most frequently involved were C.4-6, which is the region where the greatest stress occurs when the neck is flexed (Fig. 2). Paraplegia appears to be common in the region between the third and the sixth cervical vertebrae (Fig. 3).

\section{MECHANISM OF INJURY}

Injuries to the lower part of the cervical spine occur usually from forced hyperflexion or compression or a combination of these. As in the thoracic and lumbar regions (Holdsworth 1954) the injury may be of two types, stable and unstable. The stability of the cervical spine

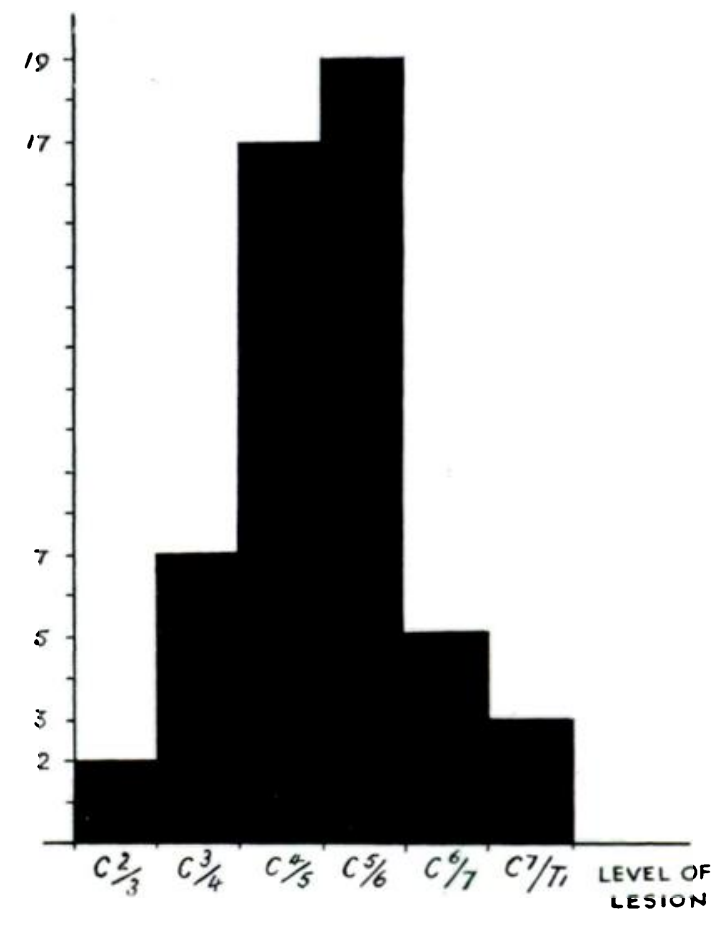

Fig. 2

Level of lesion in fifty-three dislocations and fracturedislocations below C.2.

depends mainly on the integrity of the interspinous ligaments and of the ligamentum nuchae. Ellis (1946) found that in every patient with fracture-dislocation of the cervical spine operated upon by him there was evidence of severe damage or rupture of these ligaments. This has

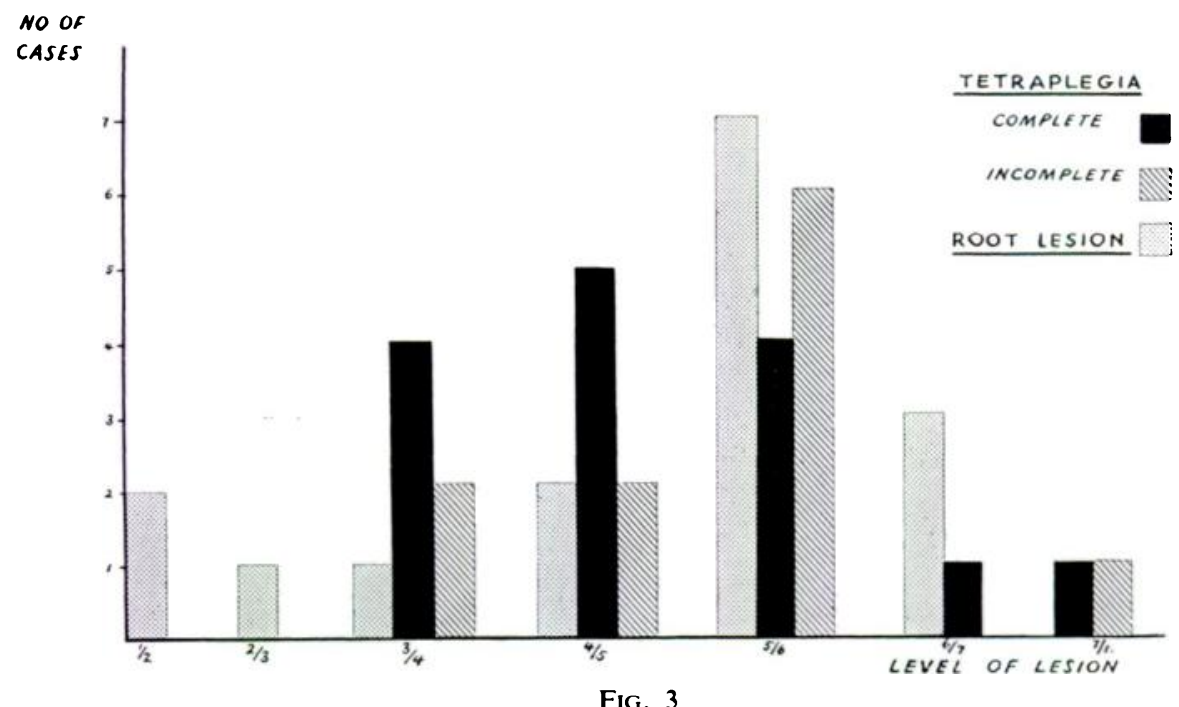

Neurological complications and level of lesion.

been so in the present investigation. Minor degrees of compression of the intervertebral body may not lead to instability; but a major crush is likely to do so, probably because of an associated lesion of the interspinous ligament, permitting dislocation of the articular facets.

VOL. 39 B, NO. 1, FEBRUARY 1957 
F. C. DURBIN

Since the facets do not lie in a transverse plane but are directed obliquely forwards and upwards, forward displacement of the upper vertebrae is facilitated by a flexion force which ruptures the posterior anchorage of soft tissue or bone. Sometimes a radiograph of the cervical spine after injury is seemingly normal except for a fracture of the spinous process. This may be an indication of damage to the interspinous ligaments and thus of probable instability which may lead to subluxation or dislocation. Fractures of the spinous processes do not often unite by bone.

Any flexion injury may cause instability of the cervical spine. Certainly a violence applied to the neck that is sufficient to fracture bone may easily tear the posterior ligaments and soft tissues that are maintaining stability, and permit displacement of the upper vertebrae. Perhaps this is a reason why fractures of the cervical spine are so often complicated by dislocation.

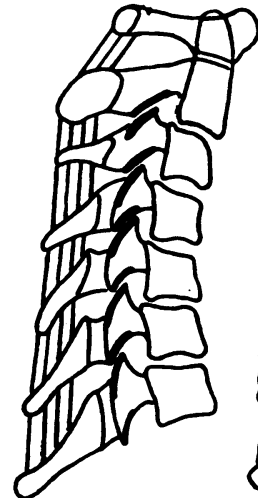

Fig. 4

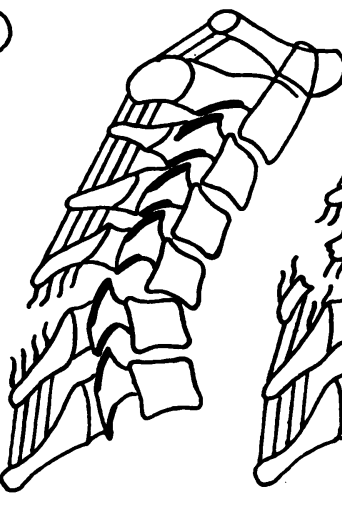

Fig. 5

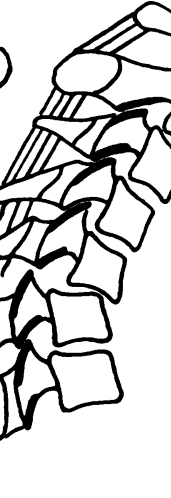

Fig. 6

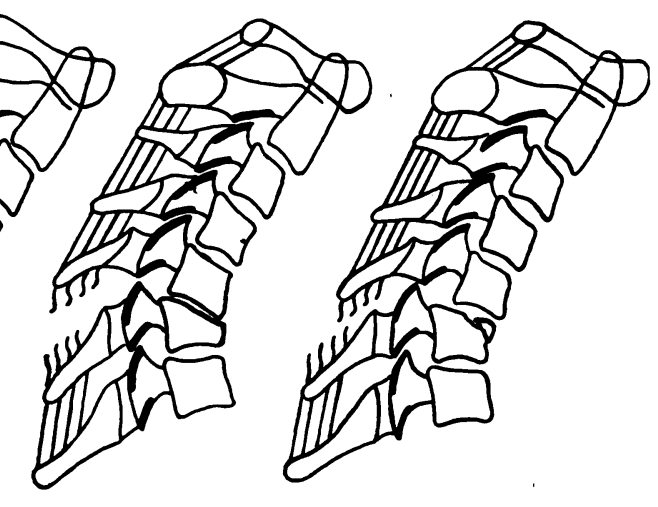

Fig. 7

Fig. 8

Drawings from radiographs showing four common types of cervical vertebral injury. Figure 4-Normal flexed cervical spine. Figure 5-Dislocation without fracture. Figure 6-Dislocation with fracture of spinous process. Figure 7-Dislocation with compression fracture of inferior vertebral body. Figure 8-Dislocation with fracture of anterior margin of inferior vertebral body.

\section{TYPES OF INJURY}

The injuries sustained by the lower cervical vertebrae are of three types (Figs. 4-8): 1) fractures; 2) dislocations; 3) fracture-dislocations.

Fractures-A fracture may take the form of a compression fracture of the body, a fracture of one or both sides of the neural arch without displacement, or a fracture of the spinous processes. Eastwood (1940) advocated early activity after these fractures, and advised brief recumbency followed by the application of a moulded leather collar which should not be worn for more than two months. He adopted this course after noting the excellent results that occurred in patients who for various reasons had never been immobilised in the traditional Minerva jacket, which appeared to lower morale and produce unnecessary discomfort and mental trauma. In the compression fracture, as might be expected, this treatment is often followed by some collapse of the affected vertebra, which is unimportant because the vertebra fuses rapidly to its neighbours by an anterior buttress of bone, with excellent functional and cosmetic results. Before undertaking this form of treatment, however, it is wise to investigate the stability of the spine by taking lateral radiographs in flexion.

Dislocations-These are more common than is realised. Many may be incorrectly described as fracture-dislocations, because it is not always easy to interpret lateral radiographs of the neck and there is a widespread belief that forward displacement does not often take place without an associated fracture of the articular processes or laminae. Dislocation, however, may occur without fracture if the posterior ligaments are torn. Displacement may also occur spontaneously in patients with spondylolisthesis of the neural arch (Durbin 1956). 
Fracture-dislocations-As previously stated, a severe compression fracture is nearly always associated with dislocation of the articular facets or with their fracture. Dislocation is not infrequently accompanied by a minor compression fracture. In cases of fracture-dislocation the upper vertebra always moves forward on the lower. The anterior part of the body below the upper vertebra may be fractured and move forward with the upper one. The displacement is often unequal on the two sides; so asymmetry of the head and neck may be obvious clinically.

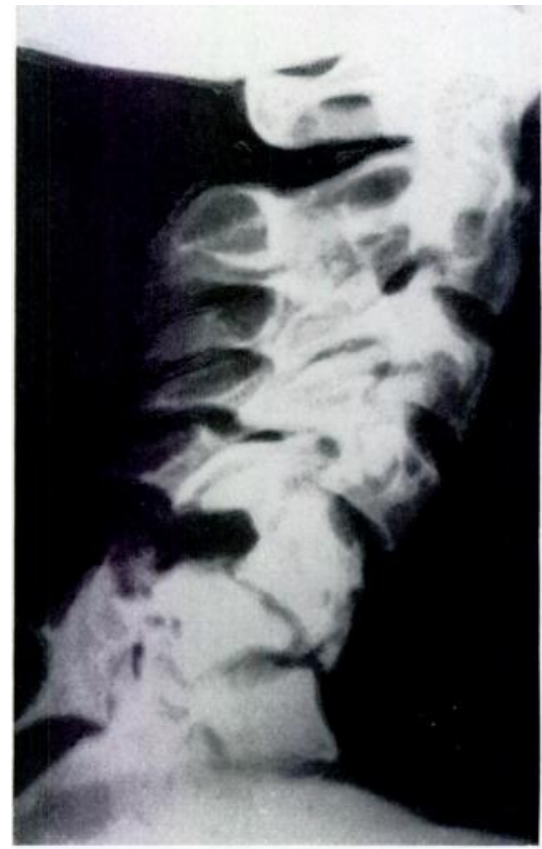

FIG. 9

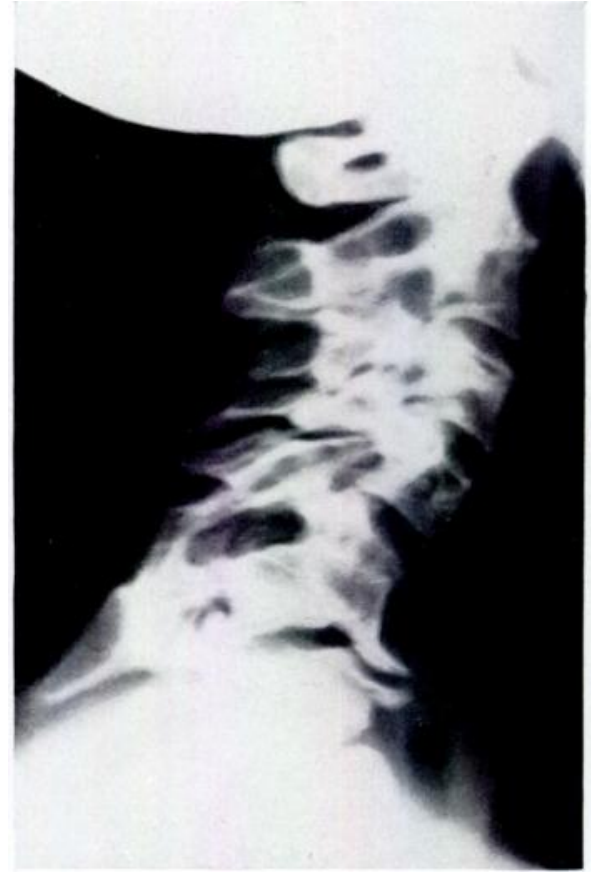

FIG. 10

Case 1. Figure 9-Radiographs one year after injury, showing dislocation of C.5 on C.6. The condition was not diagnosed for several weeks. The patient complained merely of pain in the neck and some weakness in the right arm. Figure 10-Ten years later there is solid bony fusion of the affected vertebrae anteriorly and posteriorly. There had been no fixation of any kind.

\section{DIAGNOSIS}

Any patient who gives a history of a fall may have a cervical dislocation. This may easily be overlooked in the presence of other injuries, because the neck symptoms may not be marked and attention is directed to more obvious injuries such as a fracture elsewhere. An orthopaedic surgeon serving in the last war as a parachutist injured his neck through a bad fall and was seen by a number of his orthopaedic colleagues before the condition was diagnosed as a dislocation. Radiographic examination is essential after any injury involving the neck. The antero-posterior view is seldom helpful. The lateral views are important and must include one in flexion; otherwise a diagnosis of subluxation may be missed because the lateral film in extension may show nothing abnormal. Such flexion radiographs must be taken in every case of neck injury if the views in extension are normal, because they may hold the key to the diagnosis. Flexion views are also useful after immobilisation in plaster, to determine whether there is any instability. They may give valuable information in cases of cervical injury with cord or root involvement in which a lateral radiograph in extension shows no lesion. Provided the neck is not overflexed and the manoeuvre is carried out carefully by the surgeon himself there should be no danger of increasing the neurological damage. The most extreme dislocation in this series was seen in a nurse who for some weeks had been 
treated abroad for "fibrositis" after a road accident in which she was thrown out of a jeep. Eventually radiographs revealed almost complete forward displacement of the fifth cervical vertebra on the sixth. She made a complete recovery without operation or fixation of any sort; the vertebrae fused spontaneously (Figs. 9 and 10). This is a common observation. It is surprising that patients who have either refused treatment or have received inadequate treatment because of mistaken diagnosis should be free from symptoms and signs. This does emphasise, however, the importance of a careful examination of the neck after head injuries because it is easy to miss a serious dislocation.

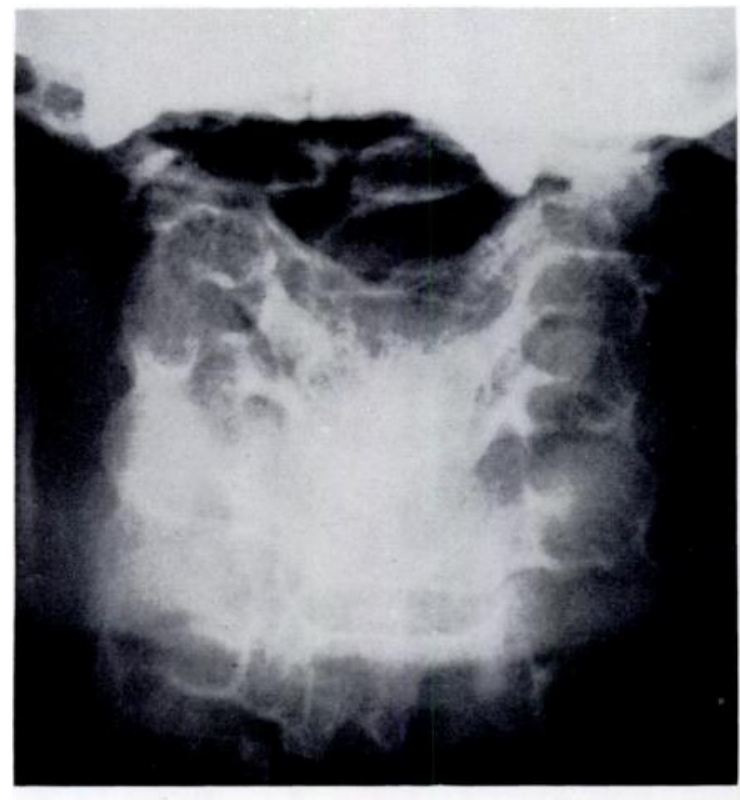

FIG, 11

Case 2-Radiographs one year after injury showing comminuted fracture of the atlas with forward displacement of the fragments. This patient had severe pain in the distribution of the great occipital nerves.

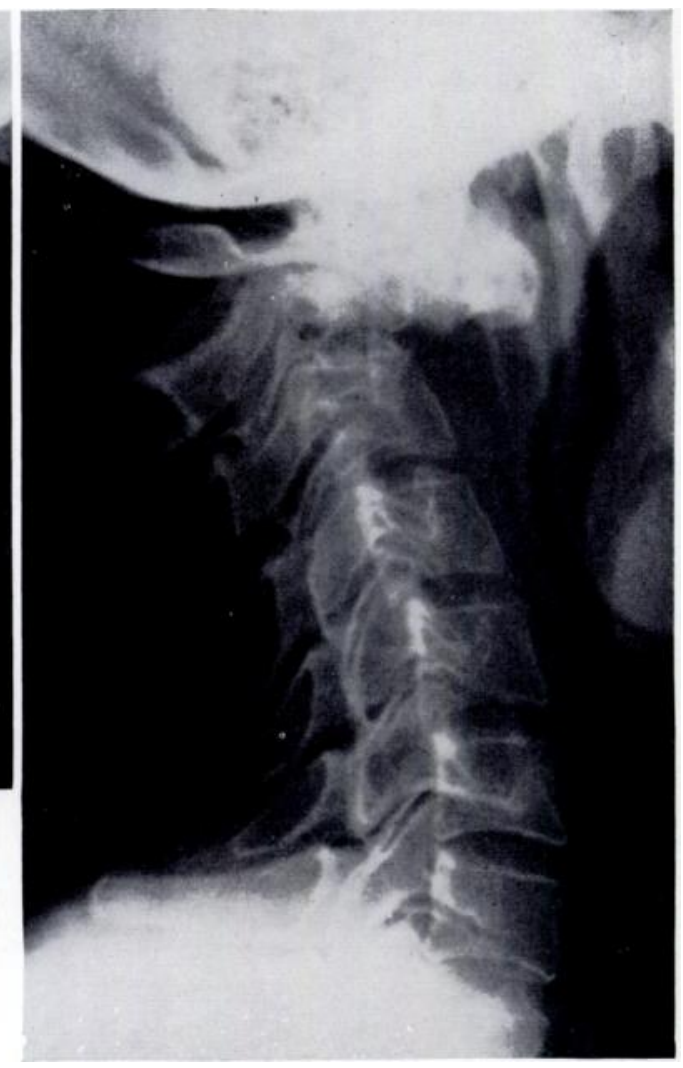

Although it will not be discussed here, fracture-dislocation of the atlas (Jefferson 1920) should be mentioned, for it is easily missed unless kept in mind in the differential diagnosis. The essential points are a history of recent injury (usually a blow or fall on the head), rigidity of the neck, limitation of head movement and perhaps neuralgia or anaesthesia of the great occipital nerve. The fracture is easily recognised in a good lateral radiograph, but the area is a difficult one for radiography. A patient seen with this condition had been treated for some months elsewhere for "fibrositis" of the neck (Fig. 11). He had intractable pain in the great occipital area. The radiograph revealed a typical fracture-dislocation of the atlas. Immobilisation in plaster, followed by the wearing of a Polythene collar for six months, relieved the symptoms.

\section{INJURY TO THE SPINAL, CORD}

When the cervical spine is dislocated it is incredible that the spinal cord should escape injury, especially when there is marked displacement. Probably there is evidence of neural injury in over half the cases (Tables II and III): the cervical cord may be crushed or the nerve roots at the site of the injury may be torn or bruised. Complete tetraplegia is nearly always 
fatal, death usually occurring from broncho-pneumonia with hyperpyrexia a few days after the injury. The cause of the hyperpyrexia is obscure but it is probably due to an extension upwards in the cord of haemorrhage or oedema. As Barnes (1948) observed, one of the most puzzling features of injuries of the cervical spine is the lack of correlation between the degree of vertebral displacement and the severity of the spinal cord lesion. There are patients with no radiographic evidence of bone injury in whom the cord is irretrievably damaged. Others, with severe dislocation, may have no paraplegia. In the absence of radiological evidence of bone damage the cause of the paraplegia in flexion injuries has been explained by assuming that a dislocation of the neural arches had undergone spontaneous reduction. But there is now evidence that in such cases disc protrusion may be the cause of the cord lesion. Hyperextension injury of an arthritic spine is the usual cause of paraplegia in patients over fifty years of age.

TABLE III

InCidence and Nature of Neural Damage

\begin{tabular}{|c|c|c|c|c|}
\hline \multirow{2}{*}{$\begin{array}{c}\text { Number of } \\
\text { patients with } \\
\text { neurological } \\
\text { symptoms }\end{array}$} & \multirow{2}{*}{$\begin{array}{l}\text { Number of } \\
\text { patients with } \\
\text { root } \\
\text { symptoms }\end{array}$} & \multicolumn{3}{|c|}{ Number of patients with cord symptoms } \\
\hline & & Complete & Incomplete & Total \\
\hline 42 & 16 & 15 & 11 & 26 \\
\hline
\end{tabular}

In the present series there were two cases of paraplegia without initial radiological evidence of bone injury. In one of the patients radiographs two weeks after the injury showed narrowing of the disc space between C.3-4 with slight forward subluxation of C.3. In the other, radiographs two months after the injury showed a fracture of the spinous process of C.4 with a minor compression fracture of C.5 suggesting a lesion at this level. Both patients had incomplete tetraplegia and both made a satisfactory recovery.

Although no obvious abnormality may be noted in the radiographs of such cases, attention should be paid to the narrowing of a disc space, minor compression of a vertebral body, fracture of a spinous process, avulsion of osteophytes when osteoarthritis is present, or anterior marginal fractures of the vertebral body. Any one of these may indicate the site of the cord lesion.

Pressure on nerve roots gives rise to tingling, anaesthesia or paresis in the upper limbs. These symptoms may persist in unstable or unreduced lesions and may necessitate operative treatment later.

There were only three cases of hyperextension injury, one with incomplete paraplegia and two with root damage.

All dislocations with neurological involvement demand prompt reduction to ensure the best possible chance of recovery. In cases of incomplete tetraplegia rapid recovery has been noted after early reduction, but recovery has not occurred when the cord lesion has been complete for more than twenty-four hours, and in fact only one of the patients with complete tetraplegia is still living.

\section{MORTALITY}

Fifteen out of the total of seventy-five patients died ( 20 per cent), fourteen with complete tetraplegia. One death occurred from coronary thrombosis a week after a cervical injury without neurological complications. Another patient died from causes unrelated to the injury five years later. Mortality rates reported by other surgeons are: Blasius (1869) 92.6 per cent; Langworthy (1930) 30 per cent; Ellis (1946) 16 per cent; Birkett (1950) 23 per cent.

VOL. 39 B, NO. 1, FEBRUARY 1957 


\section{TREATMENT}

Until the beginning of this century treatment did not greatly influence the mortality rate, which was very high. The striking reduction in the mortality may be due to the discovery of x-rays by Röntgen in 1895, which enabled the diagnosis of dislocation to be made when the clinical signs were not marked, to improved methods of manipulation (Walton 1893, Taylor 1924) and to the increasing use of plaster immobilisation. Although it was practised for many years, manipulation under anaesthesia may not only fail to reduce a dislocation of the neck but it may in fact increase the degree of paralysis. This happened in one patient here. Continuous traction with the Glisson sling has been used, but this cannot be maintained for long in a conscious patient because of the discomfort and liability to pressure sores if considerable weight is applied. It is now recognised that skull traction is the safest and most effective method of reduction, and is more comfortable for the patient. Crutchfield's "ice-tong" calipers are the simplest and are easier to apply than the more commonly used Blackburn apparatus. The drill holes should be made in a vertical line above the external meati under local anaesthesia. Reduction can then be effected either rapidly or slowly. Traction with forty pounds or more can be applied with the neck slightly flexed initially. This manoeuvre succeeds in unlocking the facets. There is no danger in using considerable weight for a short time because the neck muscles are very powerful. As Ellis (1946) pointed out, trapeze artists in a circus may hang by their teeth without any trouble.

In the absence of cord or root damage it is not essential to obtain reduction as an emergency procedure although it is reasonable to do so. The large number of satisfactory results reported after delayed or incomplete reduction bears this out. In most cases the cervical spine has become stable in a few months, the buttress of bone forming in front of the body below the lesion, giving support to the body of the vertebra above.

Sometimes even traction and manipulation will fail to reduce a dislocation. In such a case radiographs taken obliquely may be helpful in determining the cause of failure; interlocking of articular facets is usually responsible. If reduction cannot be obtained by traction, an open operation will be necessary. The facets are unlocked by the use of bone levers or by nibbling away the processes with bone forceps. Open reduction offers the advantage that the spine can be wired and grafted at the same time and the patient's convalescence thereby shortened. Four patients in this series had locked facets and were dealt with in this manner.

Very occasionally open operation fails to secure complete reduction, possibly because of interposition of disc substance. This happened in one case. The spinous processes were wired together and a Minerva plaster was applied. The wire subsequently fractured but the spine became stable and fused posteriorly as well as anteriorly by bone, with a satisfactory functional result (Figs. 12 to 15 ).

Recurrence of displacement is very difficult to prevent. A Minerva jacket is no safeguard. Brookes (1933), Cone and Turner (1937) and Ellis (1946) believed that the only sure method of holding the reduction was by open operation to wire and graft the affected vertebrae. Redislocation occurred eight times in this series-three times after immobilisation in plaster for six months. In one of these cases radiographic views in flexion were taken when the plaster was removed and showed evidence of instability. Within three months complete redisplacement had occurred. The patient had a fracture of the spinous process as well as the dislocation (Figs. 16 to 23 ).

In the two remaining cases dislocation was present without fracture, and pain after removal of the plaster caused further radiographs to be taken which revealed that redislocation had occurred.

Displacement occurred twice in patients with uncomplicated dislocations immobilised in plaster for three months. Two patients with spinous process fractures without initial radiographic evidence of dislocation who were treated with extension exercises showed 


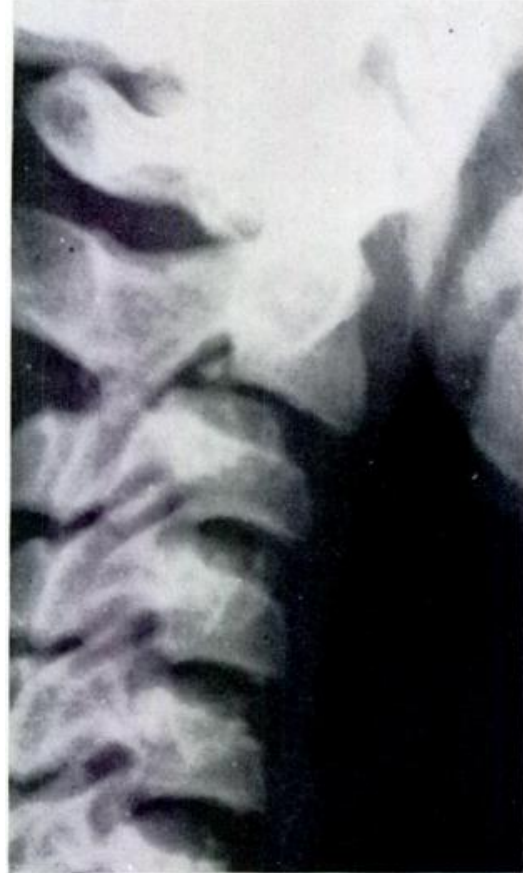

Fig. 12

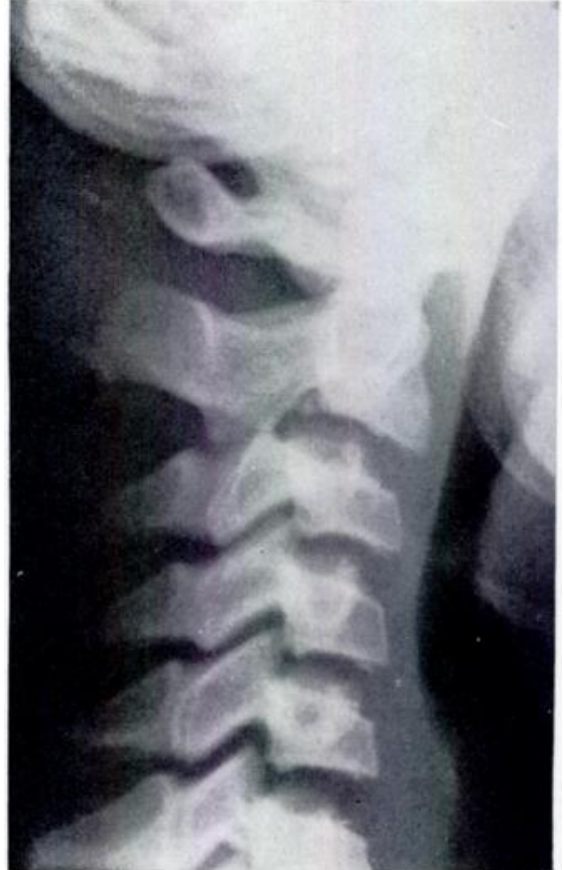

Fig. 13

Case 3-Dislocation of C.2 on C.3 with locked facets. Figure 12-Initial radiograph. Figure 13-The facets could not be unlocked with $50 \mathrm{lb}$. traction.

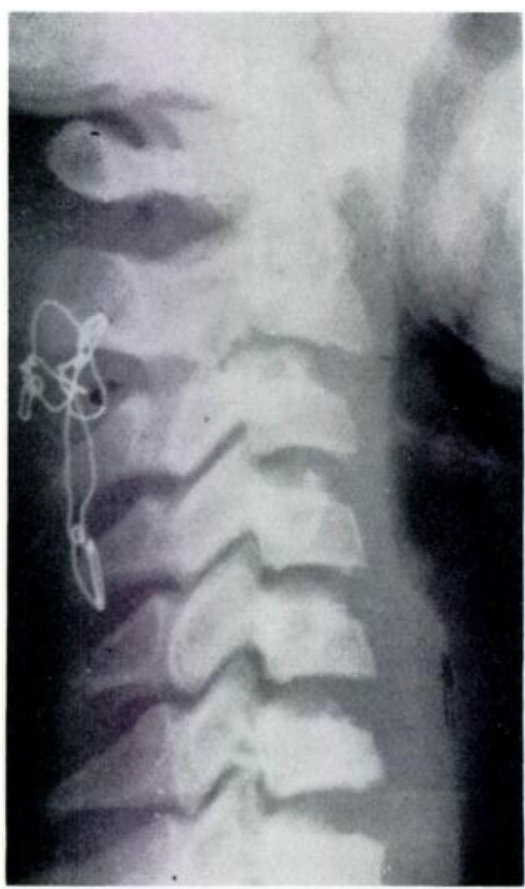

Fig. 14

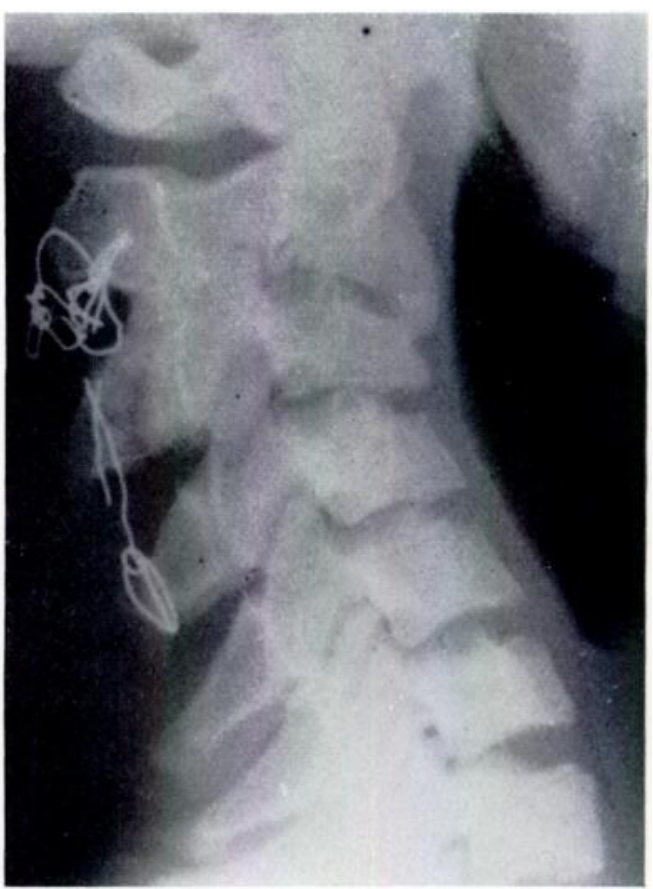

Fig. 15

Case 3. Figure 14-The facets could not be unlocked by open operation. The spinous process of C.2 was wired to C.4. (The spinous process of C.3 is nearly always small and fragile.) Figure 15Two years later there was sound fusion posteriorly but displacement had recurred and the wire had fractured.

VOL. 39 B, NO. 1, FEBRUARY 1957 


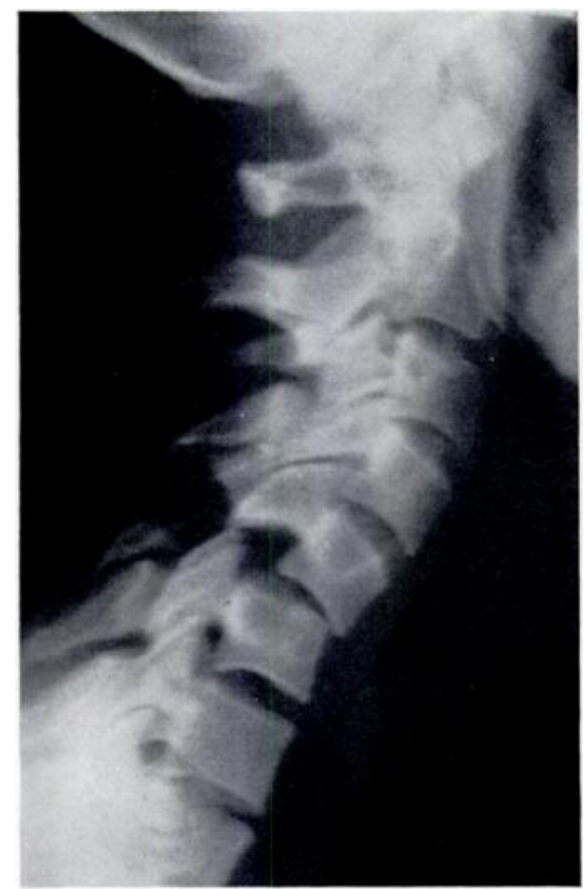

FIG. 16

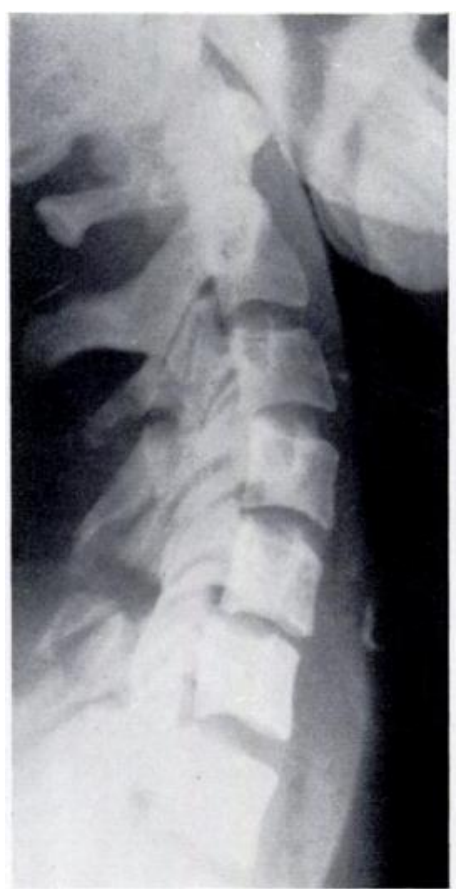

Fig. 17

Case 4-Fracture-dislocation of C.5 on C.6. Figure 16-Initial radiograph. Note fracture of the spinous process of C.5. Figure 17-After reduction by skull traction.

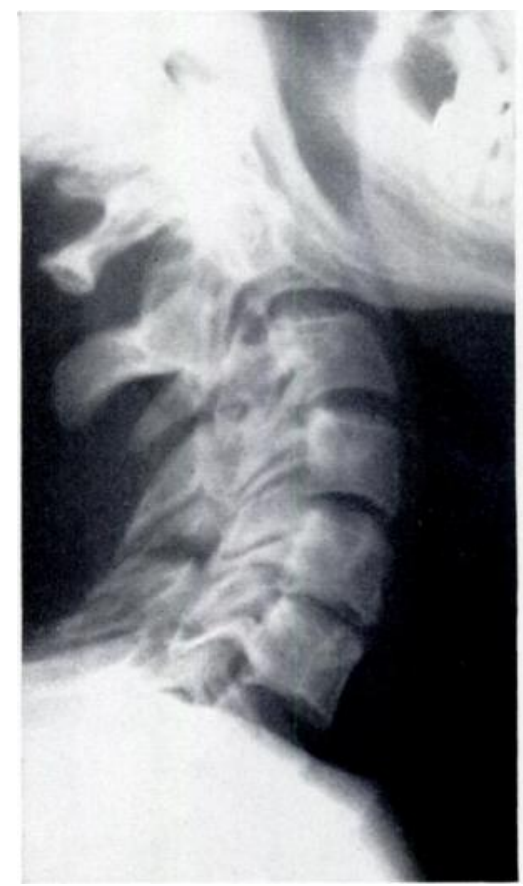

FIG. 18

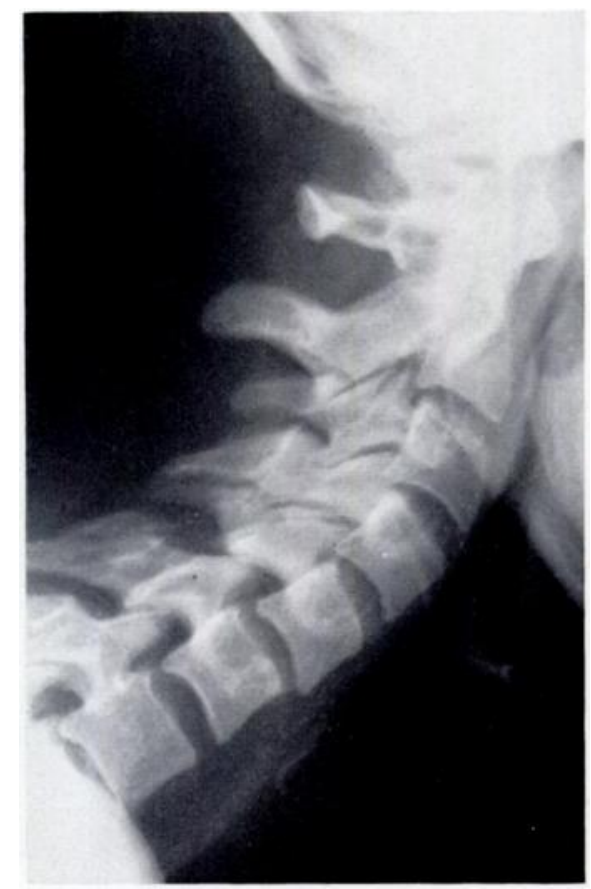

Fig. 19

Case 4. Figure 18-Radiograph in extension after six months' fixation in plaster: no displacement. Figure 19-Radiograph in flexion at the same time showed slight forward subluxation. 


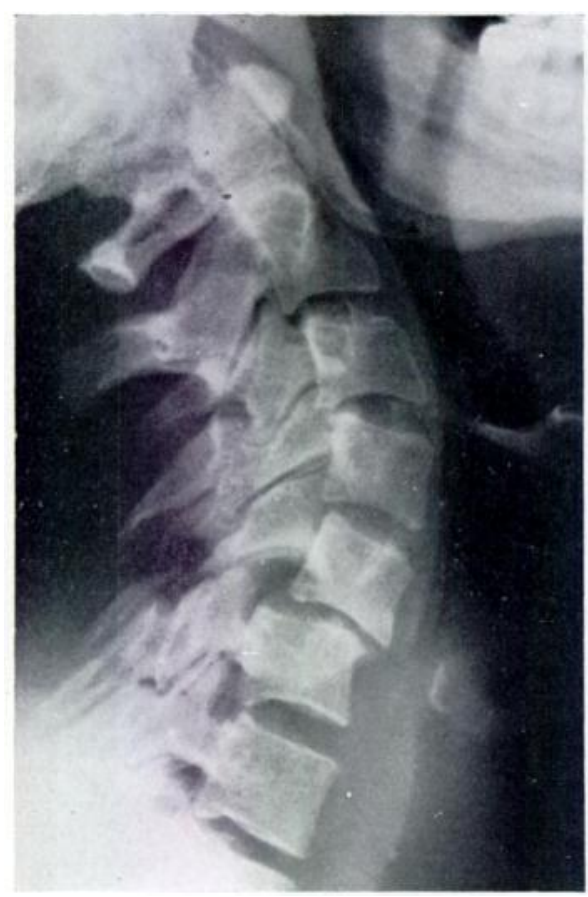

Fig. 20

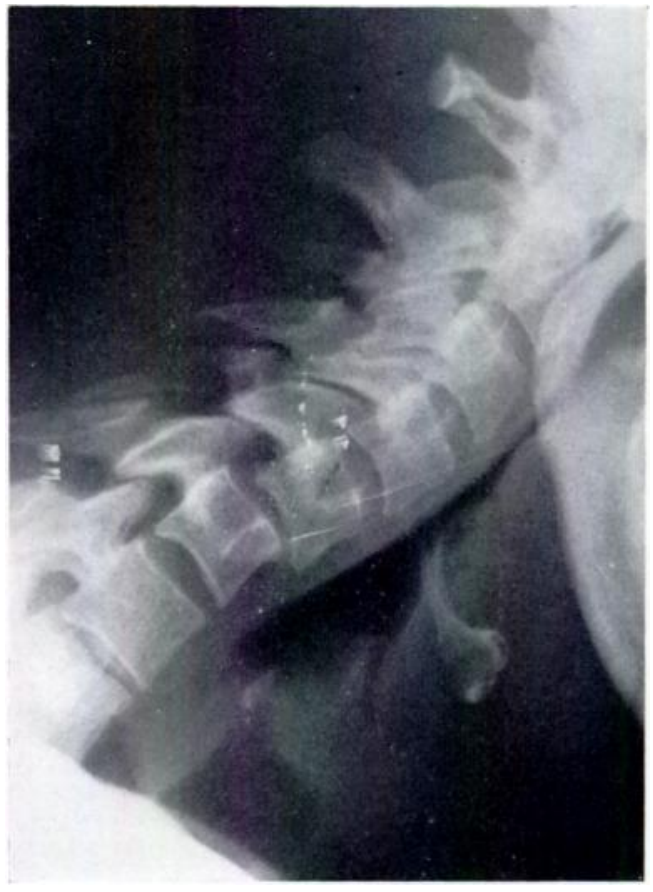

Fig. 21

Case 4-Three months after the plaster fixation was discontinued radiographs in extension (Fig. 20) and in flexion (Fig. 21) showed stability in the displaced position.

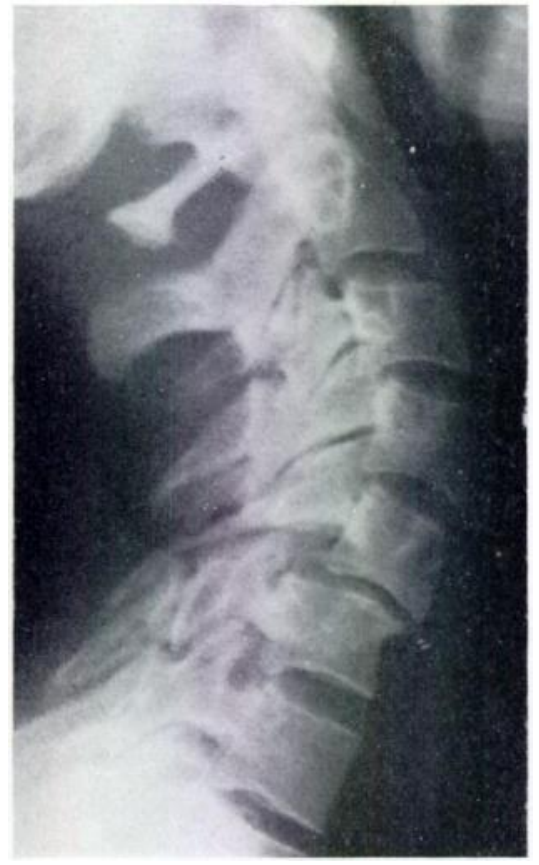

Fig. 22

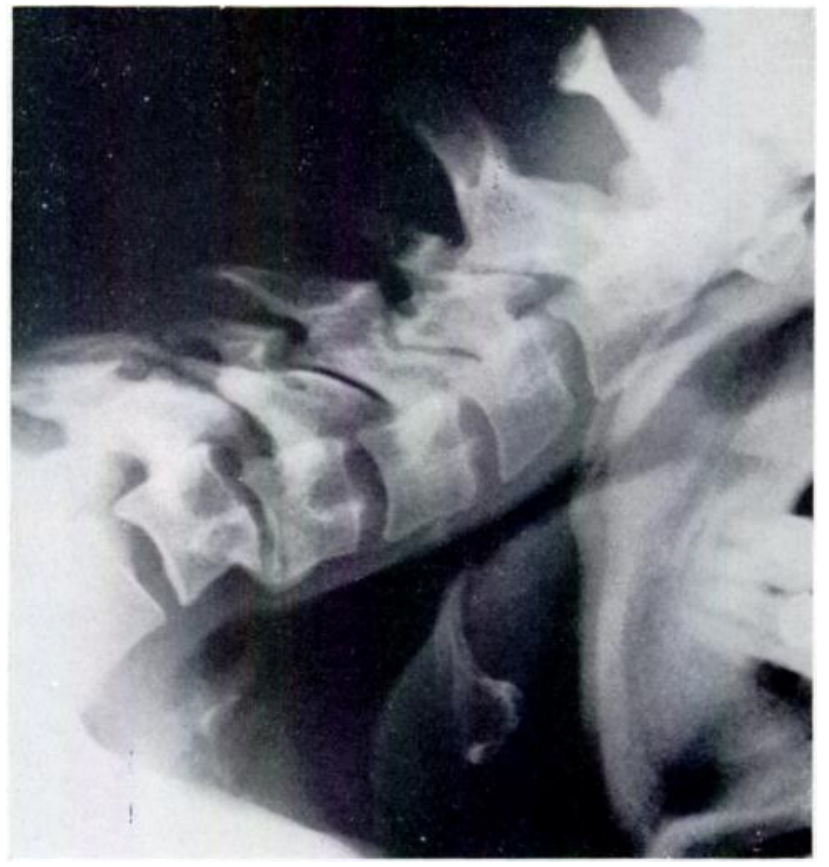

Fig. 23

Case 4-A year after removal of plaster radiographs showed bony fusion in front. 


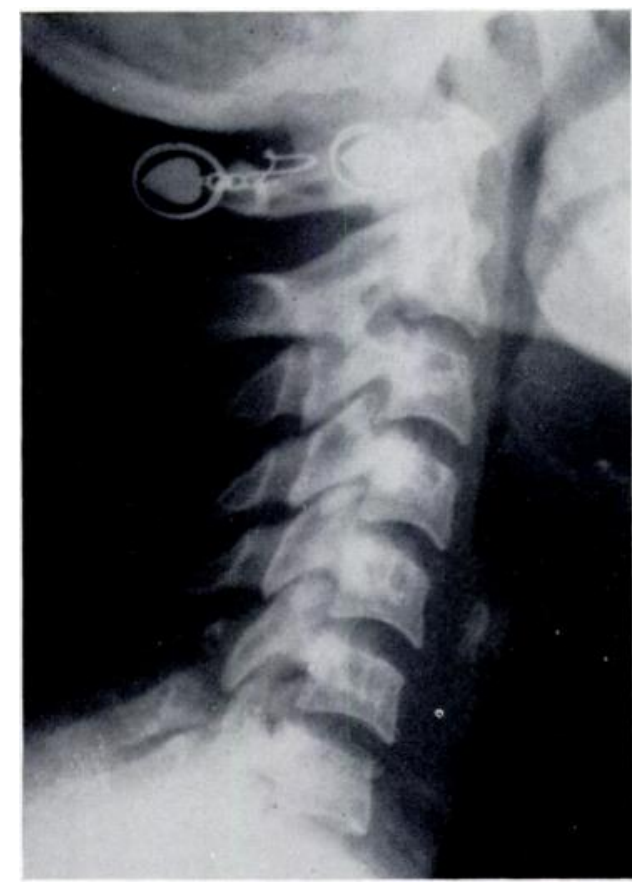

Fig. 24

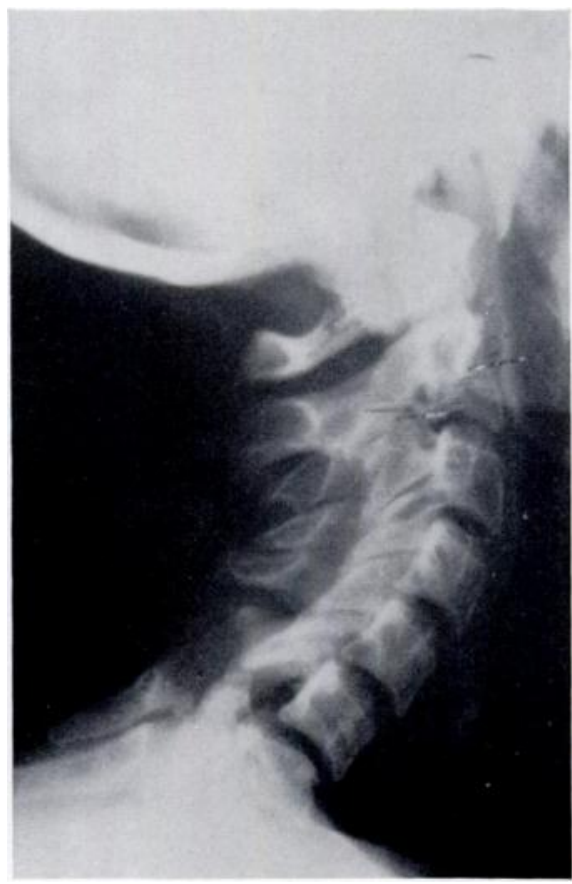

FIG. 25

Case 5. Figure 24-Radiograph of cervical spine in a woman of twenty-two with a fracture of the spinous process of C.6. She had good movement but some pain on flexion. She was treated with active extension exercises. Figure 25-Condition three weeks later when she complained of increased pain in the neck. Movements were then much restricted and painful.

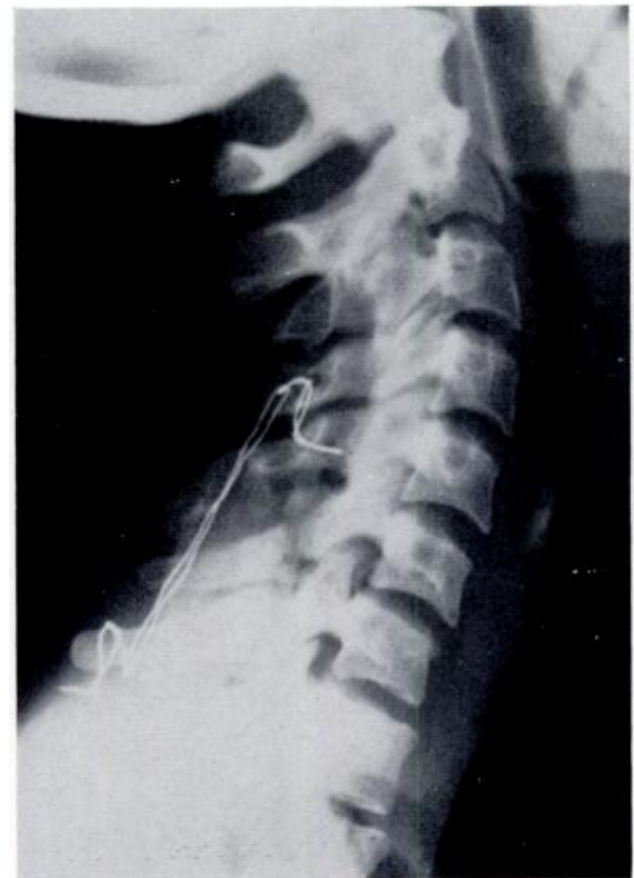

Fig. 26

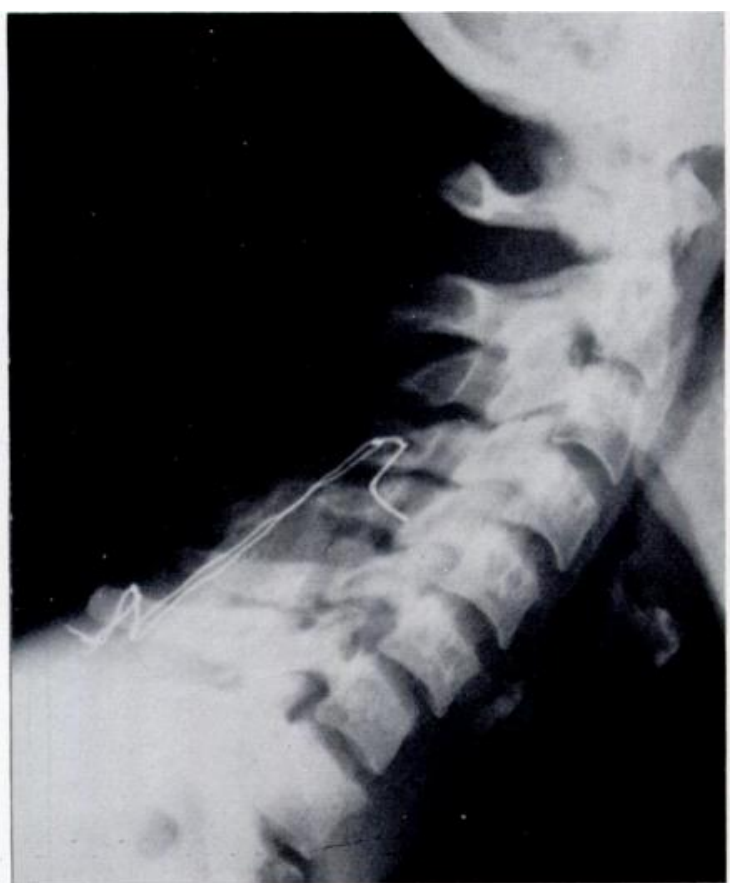

Fig. 27

Case 5-Radiographs in flexion (Fig. 26) and in extension (Fig. 27) three months after wiring and grafting, when fixation was discontinued. 


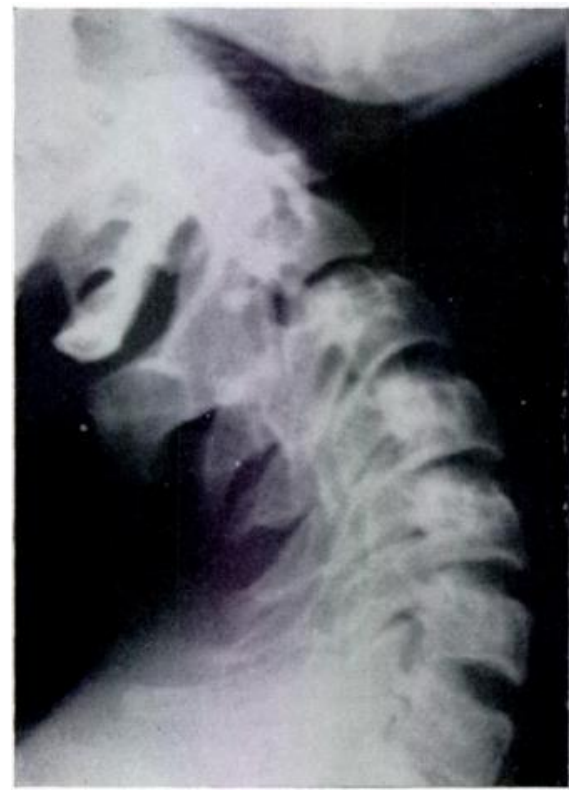

Fig. 28

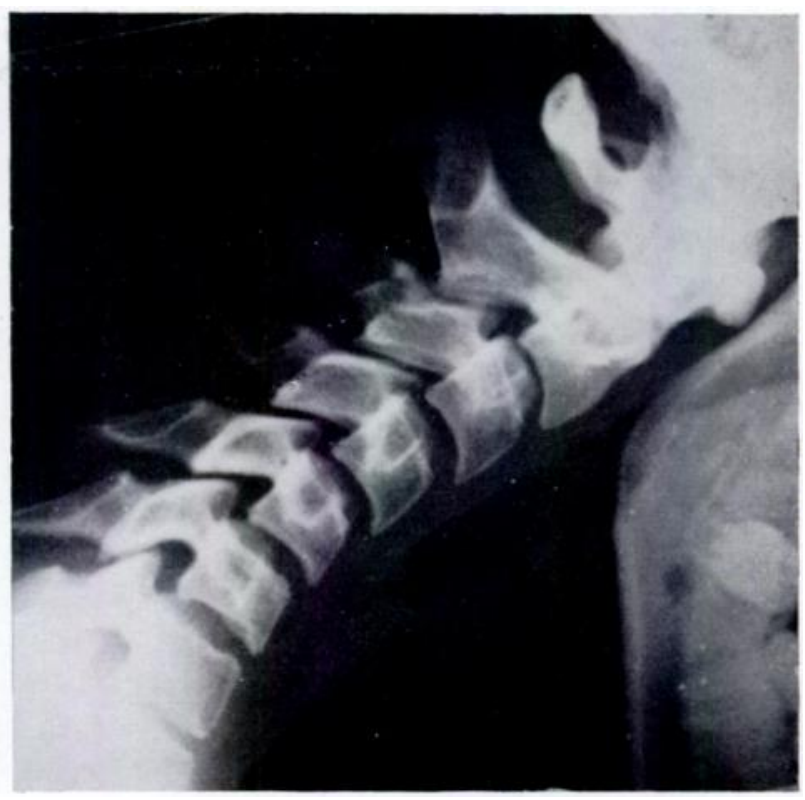

Fig. 29

Case 6-Girl with root svmptoms on neck flexion twelve weeks after a fall from a bicycle. Figure 28-Radiograph in extension showed no abnormality. Figure 29-Radiograph in flexion showed subluxation of C.4 on C.5.

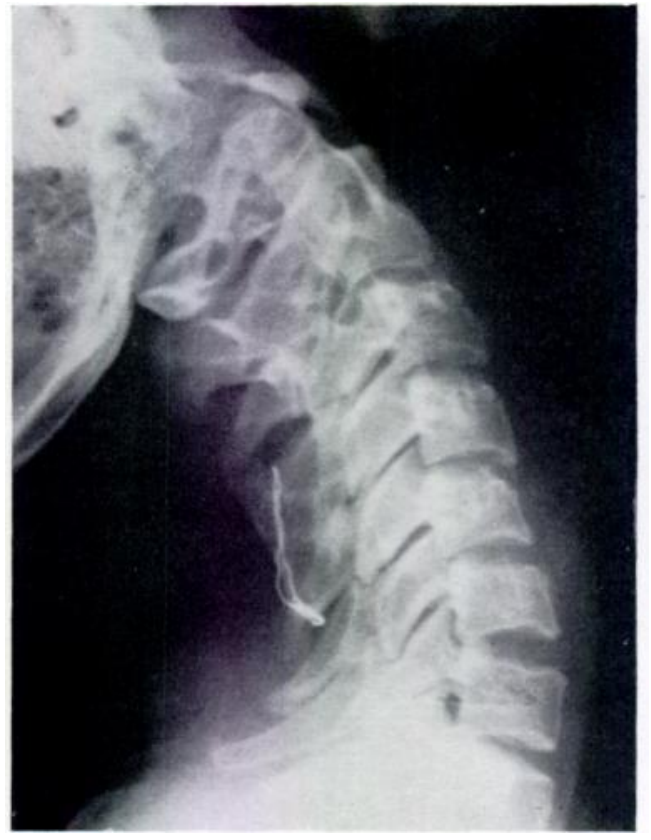

FIG. 30

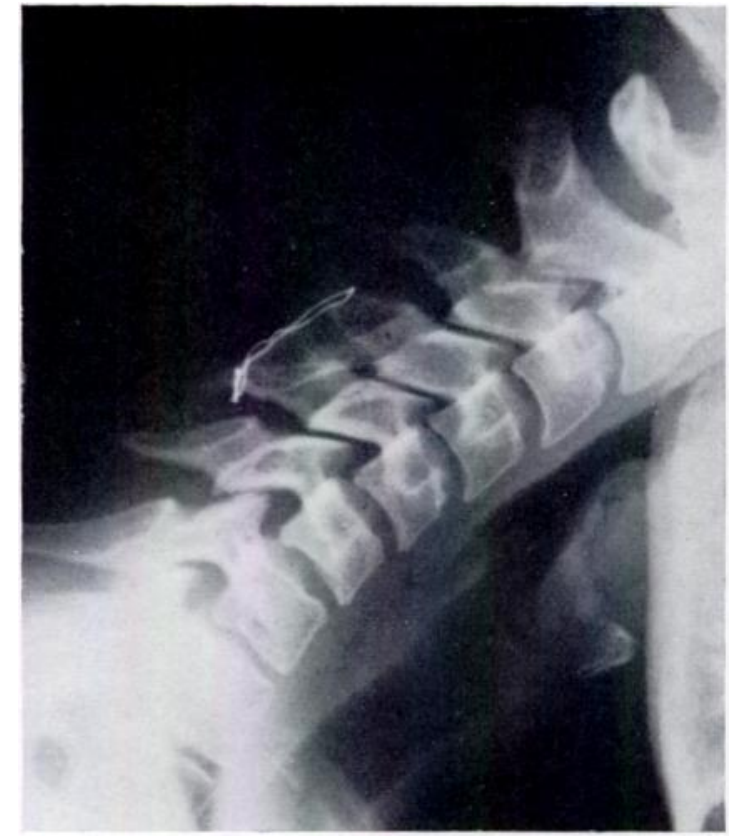

Fig. 31

Case 6--Radiograph in flexion (Fig. 30) and in extension (Fig. 31) three months after a local graft and wiring.

VOL. 39 B, NO. 1, FEBRUARY 1957 
dislocations after a few weeks of treatment. The displacement was revealed by radiography after the patients had complained of increasing pain in the neck (Figs. 24 to 27).

In one instance persistent pain in the neck for six weeks after an injury was found to be due to subluxation of the fourth cervical vertebra on the fifth, seen when the neck was flexed. The pain was relieved by local bone grafting (Figs. 28 to 31 ).

Possibly the incidence of redislocation is higher than is supposed, for radiographs are not always obtained three or four months after the plaster has been removed.

Bony fusion between the bodies of the affected vertebrae nearly always takes place eventually, whether or not the dislocation is reduced; and there may be a surprising amount of displacement without marked clinical deformity or symptoms. Nevertheless, the cervical spine cannot be considered stable and the danger of cord damage cannot be removed until

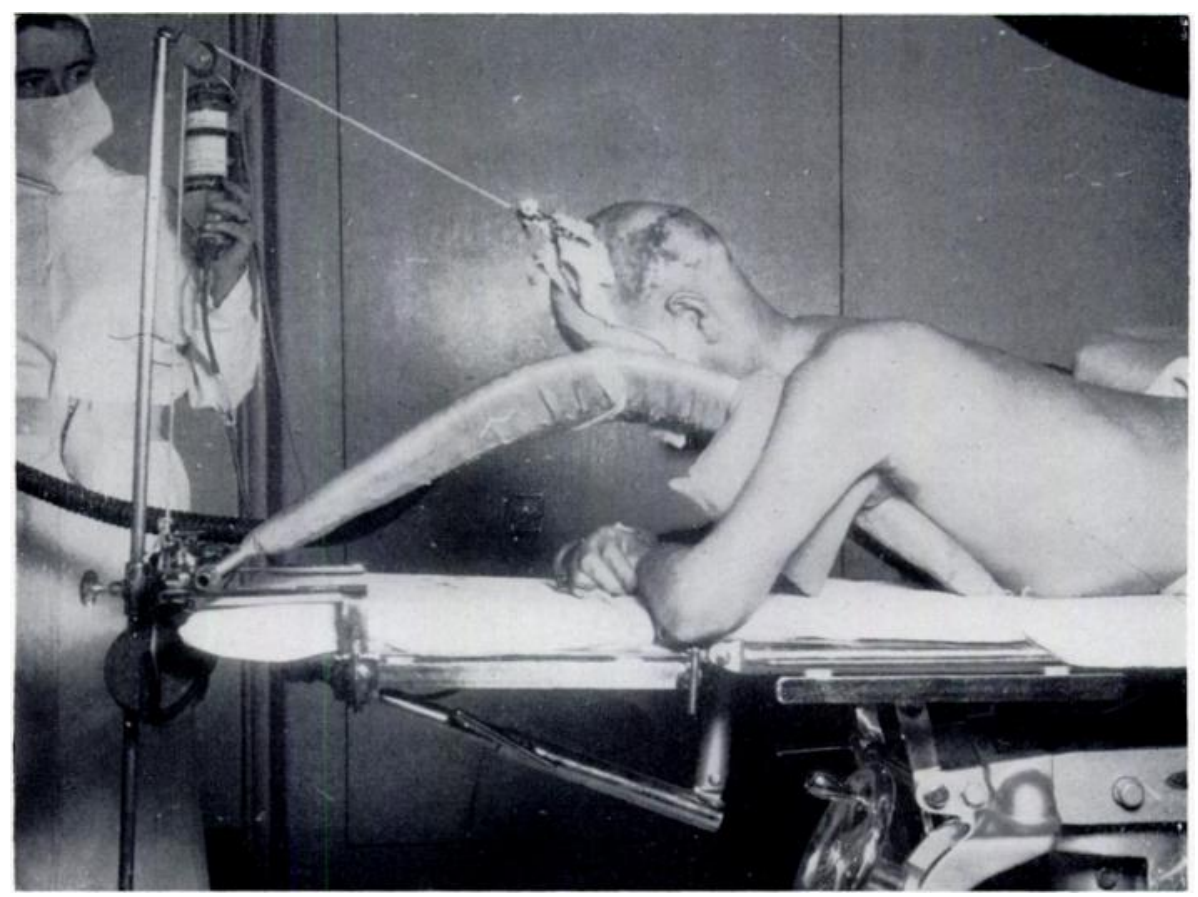

FIG. 32

Patient on convex saddle frame with skull traction preparatory to operation.

fusion has occurred. It is necessary therefore to protect the neck by a plaster or splint for some months until stability is ensured. Birkett (1950) considered that only a small field was left for operative treatment and then mainly for the late reduction of cases with locked facets. He also considered that two or three months' immobilisation in plaster was sufficient for soft-tissue repair. Two or three weeks' traction in recumbency was recommended before the plaster was applied. Such a programme of treatment will not prevent recurrence of the dislocation. It is impossible to predict whether a cervical spine will remain stable, but it is clear that redislocation is more likely to occur when there is also a fracture of a spinous process or a compression fracture of the inferior vertebral body. Prolonged preliminary traction serves no useful purpose, but traction for a short time is helpful, to reduce the dislocation and to allow time for the preparation of the patient when operative treatment follows.

It is reasonable to treat all patients with dislocation or fracture-dislocation by wiring and grafting as advocated by Gallie (1939) on the grounds that the spine is unstable, that 
it is impossible otherwise to ensure a satisfactory result in a patient engaged in a heavy occupation, and that prolonged immobilisation in plaster is uncomfortable, bad for morale and often ineffective.

The great advantage of early grafting is that the patient usually is able to dispense with any form of external fixation after three months. Wiring is necessary to maintain fixation until the graft takes over the strain (Figs. 26-35).

The operative technique of Rogers (1942) is easy to follow and is facilitated by the use of a metal frame such as that described by Shorbe and McBride (1950), which is easily made in any workshop (Fig. 32). Traction may be applied during the operation. Iliac bone is used for the graft. Afterwards the patient is kept supine with five pounds weight traction to steady the spine for two weeks, and then is fitted with a collar of plaster-of-Paris or polythene

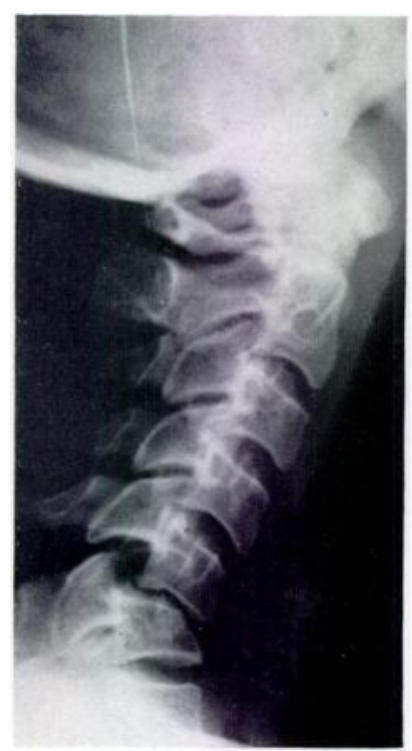

FIG. 33

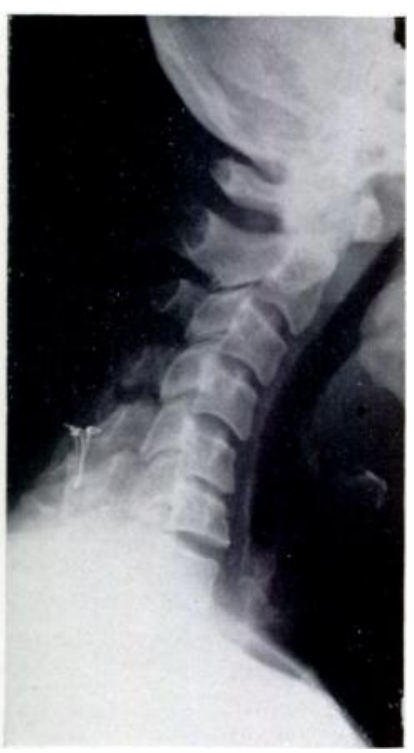

FIG. 34

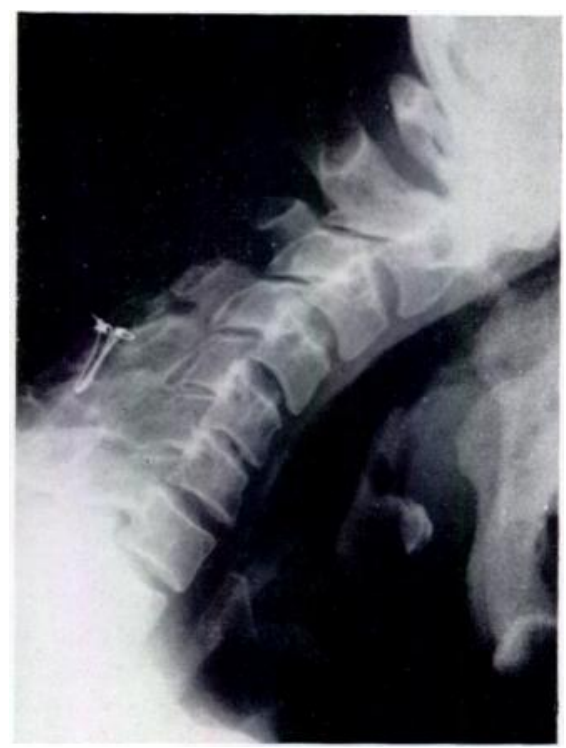

FIG. 35

Case 7-Anterior fracture-dislocation caused by a fall from a horse. Figure 33-Initial radiograph showing displacement of C.5 with compression fracture of the body of C.6. Figure 34-Extension view taken three months after wiring and grafting. Figure 35-Flexion view taken three months after wiring and grafting. The patient returned to hunting six months after the injury and although he had another fall he did not suffer any damage to his neck.

which is worn for three months. There is little permanent stiffness of the neck after operation provided that the graft fuses only the unstable vertebrae (Figs. 26-35). Sixteen patients in this series were treated by wiring and bone grafting, without mortality.

An operation for grafting may be required in old cases if there are persistent symptoms of root irritation from recurrent subluxation and persistent instability. This was necessary in two of my cases and the patients' symptoms were relieved.

\section{SUMMARY}

1. Seventy-five injuries of the cervical spine are reported. Fifty-three were dislocations and fracture-dislocations involving the third to the seventh segments.

2. The importance of careful examination in all neck injuries is stressed.

3. The injuries are divided into stable and unstable types and the causation of the instability is discussed. 
4. Plaster immobilisation for more than six months failed in some patients to prevent recurrence of dislocation.

5. Operative treatment was advised in all cases of dislocation, the spine being wired and grafted with iliac bone. This prevents recurrence and shortens the period of convalescence.

I wish to thank my colleagues at the Princess Elizabeth Orthopaedic Hospital for allowing me to include their cases, and especially Mr Norman Capener for helpful suggestions. My thanks are also due to Mr Arthur Reaney for the radiographic reproductions.

\section{REFERENCES}

Barnes, R. (1948): Paraplegia in Cervical Spine Injuries. Journal of Bone and Joint Surgery, 30-B, 234.

Birkett, A. N. (1950): Fractures and Dislocations of the Cervical Spine. In Modern Trends in Orthopaedics, p. 301. Edited by Sir Harry Platt. London: Butterworth \& Co. (Publishers) Ltd.

Blasius, E. (1869): Die traumatischen Wirbelverrenkungen. Vierteljahrschrift für die praktische Heilkunde, 102, 1. (Quoted by Ellis.)

Brookes, T. P. (1933): Dislocations of the Cervical Spine. Their Complications and Treatment. Surgery, Gynecology and Obstetrics, 57, 772.

CONE, W., and TURNer, W. G. (1937): The Treatment of Fracture-Dislocations of the Cervical Vertebrae by Skeletal Traction and Fusion. Journal of Bone and Joint Surgery, 19, 584.

Durbin, F. C. (1956): Spondylolisthesis of the Cervical Spine. Journal of Bone and Joint Surgery, 38-B, 734. EAstwood, W. J. (1940): Discussion on Fractures and Dislocation of the Cervical Vertebrae. Proceedings of the Royal Society of Medicine (Section of Orthopaedics), 33, 651.

Ellis, V. H. (1946): Injuries of the Cervical Vertebrae. Proceedings of the Royal Society of Medicine (Section of Orthopaedics), 40, 19.

Gallie, W. E. (1939): Fractures and Dislocations of the Cervical Spine. American Journal of Surgery, N.S. 46, 495.

Grogono, B. J. S. (1954): Injuries of the Atlas and Axis. Journal of Bone and Joint Surgery, 36-B, 397.

Hippocrates (1927): With an English Translation by E. T. Withington. Vol. 3. The Loeb Classical Library. London: William Heinemann.

Holdsworth, F. W. (1954): Traumatic Paraplegia. Annals of the Royal College of Surgeons of England, 15, 281.

Jefferson, G. (1920): Fracture of the Atlas Vertebra. British Journal of Surgery, 7, 407.

LANGworthy, M. (1930): Dislocations of the Cervical Vertebrae. Report of Thirty Cases. Journal of the American Medical Association, 94, 86. (Quoted by Ellis.)

Power, Sir D'Arcy (1934): The Edwin Smith Papyrus. British Journal of Surgery, 21, 385.

Röntgen, W. K. (1895): Chambers's Encyclopaedia 1950, Article X-rays. Vol. 14, p. 771. London: George Newnes Limited.

Rogers, W. A. (1942): Treatment of Fracture-Dislocation of the Cervical Spine. Journal of Bone and Joint Surgery, 24, 245.

ShORBE, H. B., and McBride, E. D. (1950): The Convex Saddle Frame. Journal of Bone and Joint Surgery, 32-A, 452.

TAYLOR, A. S. (1924): Fracture-Dislocation of the Neck. A Method of Treatment. Archives of Neurology and Psychiatry, 12, 625.

Walton, G. L. (1893): A New Method of Reducing Dislocation of Cervical Vertebrae. Journal of Nervous and Mental Diseases, 20, 609. 